\title{
Relatos sobre uma etnografia do trabalho no Polo Naval de Rio Grande: a possibilidade de uma experiência ética e estética no processo de construção dos objetos de pesquisa.
}

\author{
Reports on an ethnography of work at the Naval Pole of Rio Grande: the \\ possibility of an ethical and aesthetic experience in the process of construction \\ of research objects.
}

Pedro Marchioro'

\begin{abstract}
Resumo
Este artigo tem como objetivo trazer um relato dos métodos, práticas e técnicas utilizadas durante as pesquisas em torno dos conflitos ocorridos na cidade de Rio Grande/RS entre 2013 e 2016, o qual envolvia trabalhadores locais e estrangeiros em razão da instalação do polo naval. Tomada como um conjunto de técnicas forjadas na interação com o universo da pesquisa, a etnografia se define a partir de sua aplicação em uma dada situação singular, nos desafios a que se propõe enfrentar e no modo como potencialmente os supera. Enquanto método de pesquisa e prática epistemológica, a etnografia mostra-se decisiva para abordar eixos temáticos como o trabalho, sobretudo no que diz respeito às distintas faces e dimensões em que se manifesta na sociedade contemporânea e que escapam aos tradicionais instrumentos de análise. No mais, a etnografia oferece uma experiência enriquecedora ao pesquisador, abrindo-se para a improvisação de instrumentos através de seus níveis emocionais e sensíveis, portanto, exigindo a mobilização de componentes éticos e estéticos.
\end{abstract}

Palavras chave: etnografia, trabalho, migrações, xenofobia, polo naval.

\begin{abstract}
This article aims to provide an account of the methods, practices and techniques used during the research on the conflicts that occurred in the city of Rio Grande / RS between 2013 and 2016, which involved local and foreign workers due to the installation of the naval pole. Taken as a set of techniques forged in the interaction with the universe of research, ethnography is defined by its application in a given singular situation, in the challenges it proposes to face and in the way in which it potentially surpasses them. As a method of research and epistemological practice, ethnography is decisive for addressing thematic axes such as work, especially with regard to the different faces and dimensions in which it is manifested in contemporary society and which escape the traditional instruments of analysis. Moreover, ethnography offers an enriching experience to the researcher, opening for the improvisation of instruments through their emotional and sensitive levels, thus requiring the mobilization of ethical and aesthetic components.
\end{abstract}

\footnotetext{
1 Doutorando em Sociologia pela Universidade Federal do Paraná (UFPR). É membro do Núcleo de Estudos do Polo Naval, do projeto de pesquisa Imigrantes Haitianos no Paraná: preconceito, integração e capital mobilidade e do projeto A Reflexividade na Sociologia e nas ciências sociais contemporânea. Atualmente suas investigações se debruçam sobre as imigrações haitianas no Brasil e no mundo. Email: pedro-marchioro@live.com
} 
Keywords: ethnography, work, migrations, xenophobia, naval pole.

\section{Introdução}

O objeto que deu corpo à pesquisa de mestrado desenvolveu-se em uma configuração que continha duas figuras centrais, os trabalhadores locais e os trabalhadores estrangeiros. Os primeiros assumiram o grupo dos "gaúchos", operando a sobreposição das demarcações das diferenças internas - referentes aos "pelotenses", "bageenses", "riograndinos", "mergulhões", etc. - e se articulando a partir do enfrentamento desse (novo) inimigo comum: os "baianos". Estes, por sua vez, aplicando-se aos trabalhadores estrangeiros, foram assim denominados pela população local em uma tentativa de depreciar as posições que vieram a ocupar. À diferença dos "gaúchos", os indivíduos denominados "baianos", sobretudo pelo levantamento e identificação de atributos corporais e comportamentais, não se identificavam subjetivamente com este signo, apesar de compreender que a denominação se endereçava a eles.

Durante a pesquisa, optou-se por utilizar os próprios termos construídos pelos agentes em disputa para referenciar os grupos, tomando o cuidado de sempre enquadrá-los entre aspas (GUBER, 2011, p. 98), por duas razões: primeiro devido ao caráter etnográfico que a teorização fundamentada exige, de levantar categorias e tipologias enquanto "códigos in vivo", isto é, a partir das próprias imagens e significados evocados pelos informantes diretamente envolvidos (QUIÑONES, 2015, p. 120); segundo (e refreando o primeiro), com o uso das aspas opera-se uma ruptura com os sentidos atribuídos tal como enunciados por estes mesmos agentes (BOURDIEU, 2011, p. 34; CARDOSO, 2004, p. 101).

Nesse sentido, além de discussão metodológica, inerente ao tema da etnografia, faz-se imprescindivel a problematização dos pressupostos teóricos e epistemológicos que fundamentam os procedimentos em campo, isto é, afora os esforços para construir o objeto, é preciso pensar os instrumentos dessa construção. Essa problemática se estende às instituições - prefeitura, sindicatos, empresas privadas, entidades de planejamento e treinamento, meios de comunicação, etc. - que atuam na 
definição do mundo social e acabam por erguer entraves à investigação sociológica, uma vez que obrigam o pesquisador a rever as categorias e asserções com que tais instituições definem aquilo que entendem ser um "problema" da realidade. "O pré-construído", segundo Bourdieu (2011, p. 35), "está em toda a parte. O sociólogo está literalmente cercado por ele, como o está qualquer pessoa". Em outros termos, a etnografia não se faz em um vazio social, ela opera em um universo cujos elementos estão carregados dos sentidos partilhados pelo senso comum, e que perfazem uma constante disputa pela sua apropriação. Sendo assim, também o trabalho etnográfico acaba por atuar nesse campo de disputa e reconhecimento.

$\mathrm{Na}$ comparação com as metodologias quantitativas positivistas (BECKER, 2014), a etnografia se diferencia pela maneira como mobiliza a linguagem, desde sua instrumentalização em campo até a inscrição em seus trabalhos finais, de preocupação com o modo como proporciona ao leitor, através de um estilo, uma (re)vivência de determinadas questões no universo investigado. Nesse sentido, o exercício de escrita, enquanto parte do método etnográfico, encontra grande afinidade com aquele exercido por escritores romancistas ou poetas (BECKER, 2015; CARDOSO, 2004; WACQUANT, 2002).

Dada ainda a variedade de recursos de que a etnografia dispõe, encontramos nela maior flexibilidade para driblar as "armadilhas da pesquisa", podendo recorrer a diversos tipos de instrumentos de coleta, registro e análise de dados. Sendo assim, a investigação dos conflitos entre "gaúchos" e "baianos" imediatamente exigiu o deslocamento para outras categorias e dimensões de análise. A principal delas foi a questão do trabalho, suas relações internas e os modelos econômicos na qual se insere, dado que a razão dos conflitos entre nativos e migrantes radicava-se no polo naval e nas atividades laborais que ali se abriram. Tendo que no mundo contemporâneo o trabalho se encontra fortemente marcado por uma lógica de competição global, em que empreendimentos multinacionais vêm a instalar suas plantas produtivas em contextos não afeitos tradicionalmente a esses níveis de produção, há que se debruçar, com mais afinco, sobre a variável cultural que estes empreendimentos atingem. Desse modo, a 
etnografia apresenta-se como componente imprescindivel para a compreensão abrangente do fenômeno sobretudo no que tange a vinculação subjetiva dos individuos envolvidos.

Por fim, além de um relato sobre um estudo de caso no qual a etnografia foi a principal "arma”, buscará se discutir a possibilidade de se superar a representação que ainda hoje se faz do pesquisador em campo, tensionando a perspectiva clássica do sujeito de consciência racional e distanciado de seu objeto, e apontando-o enquanto sujeito plural, transpassado por múltiplos canais de estímulos e disposições, e, sobretudo, dotado de um arranjo emocional e sensitivo envolvido e mesmo construído nos contextos da pesquisa (LAHIRE, 2001; SAID, 1998).

Neste nível o pesquisador estaria tão impregnado das pré-noções comuns quanto aqueles sobre os quais investe seus questionamentos. A despeito de sua natureza social revestir de maior complexidade a relação com o universo pesquisado, e não havendo possibilidade de furtar-se a ela, cabe assumi-la enquanto recurso heurístico para a produção do conhecimento. A exposição ou "abandono" subjetivo do pesquisador ao universo de pesquisa, ou seja, a um contexto estranho e "exótico" ao seu, reserva-lhe um compromisso adicional de transbordamento de si, de abertura propositada ao inesperado, isto é, ao potencialmente perturbador. Este compromisso diz respeito à uma produção de si, ou seja, à uma ética.

\section{“Armadilhas do método"}

Em seu artigo sobre as "Aventuras de antropólogos em campo ou como escapar das armadilhas do método" (2004), Ruth Cardoso faz uma digressão sobre como a metodologia qualitativa logrou disputar, por volta dos anos 60, a hegemonia das ferramentas de pesquisa nas ciências sociais na Europa e nos Estados Unidos, e como ela foi recebida no Brasil. Neste último, segundo a autora, a absorção das metodologias qualitativas não foi acompanhada de uma revisão dos quadros teóricos e epistemológicos que norteavam o emprego das novas técnicas; não se abandonou, por exemplo, as discussões mais fiéis às análises marxistas, sobretudo no que toca à 
possibilidade de revolta das camadas populares e da revolução do proletariado.

Nesse sentido, apesar de se passar a valorizar a presença prolongada em campo, a observação participante, os registros fiéis às falas dos atores, continuou-se a operar segundo as mesmas premissas paradigmáticas anteriores, como a de que as classes operárias ou excluídas eram revolucionárias e em vias da tomada de consciência de sua missão. Segundo Cardoso, a preocupação sobressaliente nestas pesquisas era sobre os motivos das classes excluídas ainda não haverem se rebelado, e não sobre a arbitrariedade de tais asserções: “a intenção destes pesquisadores é ler, através das linhas tortas do discurso cotidiano, os sintomas que permitem manter intocável e inflexível o paradigma teórico" (2004, p.97).

Portanto, as primeiras experiências com a metodologia qualitativa estavam ainda imersas em esquemas positivistas de problematização. Tampouco houve um reexame das formas de empregar as novas ferramentas de pesquisa, e, principalmente, sobre a atuação subjetiva do pesquisador em campo, que continuou a ser considerada como um fator de distorção dos dados coletados. Estes, ainda na formulação clássica do positivismo, deveriam "falar por si mesmos" (CARDOSO, 2004).

Desse modo o cenário europeu dos anos 60 atingiu destinos parecidos ao caso brasileiro, apesar de transcorrerem caminhos bastante distintos. No caso europeu, o giro epistemológico progrediu em tal profundidade que acabou por imprimir à etnografia prerrogativas de atribuição de soberania absoluta aos agentes investigados. Na prática isso significava a redução do papel do pesquisador a não muito mais que um veículo da fala dos agentes enquanto únicos detentores da "verdade" sobre suas experiências.

Tais prerrogativas se devem às primeiras reações às correntes teóricas que reduziam os agentes a meros derivados estruturais (BOURDIEU, 2004). Passou-se a enxergar com desconfiança todo discurso que pretendia obliterar a explicação dos próprios indivíduos quanto às situações que vivenciavam. Esse novo paradigma foi profundamente marcado pela deflagração dos movimentos estudantisr e insurreições 
políticas que colocaram em questão a centralidade de toda e qualquer autoridade ocidental, tal como o maio de 68 na França, inspirados pela entrada de novos intelectuais na cena do debate, tais como Foucault, Deleuze, Hall, Ranciére e sobretudo as linhas criticas ligadas ao feminismo (HALL, 2011). Seus escritos reforçavam a suposição de que a ciência e os modelos de conhecimento em geral incorriam na "indignidade de falar pelos outros" (DELEUZE, 1992), em que o pesquisador, "esse importuno, teria a pretensão de possuir a verdade dos sujeitos melhor de que eles mesmos, adotando um ponto de vista divino sobre as coisas" (SAYAD, 1998, p. 132), tomando-os por "alienados", de acordo com a ortodoxia marxista, ou por "epifenômenos estruturais", de acordo com o estruturalismo (BOURDIEU, 2004). A essa nova ciência social um tanto "ingênua e culpada", como alega Lahire (2004), fiel ao achado de que "os atores na verdade sabem o mesmo ou muito mais que o sociólogo", o autor questiona:

\begin{abstract}
Os que pensam dessa maneira - e eles são numerosos - deveriam extrair suas consequências lógicas e se perguntar para que, nesse caso, serve um sociólogo. Pois o que ele pode fazer senão arruinar a autenticidade do mundo ao reinterpretar as maravilhas de sentidos autônomos que saem da boca dos autores? Será que bons gravadores não respeitariam mais o sentido dos atores e o "verdadeiro conhecimento sociológico" do que o mais dócil e repetitivo sociólogo? $\mathrm{E}$ se o ator comum for melhor do que o próprio sociólogo, que legitimidade tem este para lhe atribuir um diploma de sociologia? Se o relato dos atores diz mais e melhor do que o sociólogo, por que este correria o risco de destruir essa verdade em estado bruto, escrevendo sobre o sujeito? (LAHIRE, 2004, p 38)
\end{abstract}

A ressignificação do agente em relação com sua realidade e, portanto, com a pesquisa, exige, na mesma medida, a superação da noção de pesquisador enquanto desprovido de subjetividade, assim como sua implicação na produção do conhecimento.

Nos próximos tópicos, seguirei ponderando essa problemática em torno dos seguintes tópicos: como a minha subjetividade atua em campo? Como sinto aquilo sobre o qual estou interessado em investigar? Como eu, um integrante da classe $\mathrm{X}$ ou $\mathrm{Y}$, branco, universitário, relaciono-me com esta classe e cultura que não são minhas? Sinto aversão, afinidade, raiva, admiração? O que é que me diferencia (ou não) destes indivíduos? Há de fato um espaço entre nós? Sou eu um homo clausus, como indagava Elias (2011) 
separado por um invólucro epitelial ou mesmo por um conjunto de normas que alega uma individualidade indispensável para minha inteligibilidade? Ou estarei conectado intersubjetivamente ao Outro, afetando e sendo afetado, produzindo percepções sobre ele ao mesmo tempo que ele as produz sobre mim (CARDOSO, 2004)? Como posso utilizar daquilo que me é impresso no corpo para a produção de conhecimento?

\section{A construção do campo da pesquisa}

É comum que ao pensar no ofício do etnógrafo evoquemos a ideia do pesquisador em campo tomando nota de tudo aquilo que lhe passa frente aos olhos, interpelando pessoas com um gravador em mãos, indo de um lado a outro decididamente, em um “esforço encarniçado" - dirá Sayad (1998, p. 132) - por encontrar o objeto pretendido. Essa imagem, no entanto, corresponde a apenas uma parte das atividades que compõem a amplitude da pesquisa etnográfica. Há que se destacar as etapas precedentes ou entrepostas do trabalho em campo: do etnógrafo confinado em seu escritório, esquadrinhando conceitos e depurando as categorias que lhe concederão a textura heurística para apreender os sentidos apontados no plano empírico. Sendo assim, há uma variação considerável, refletida no todo do trabalho etnográfico, condizente ao conjunto dos referenciais teóricos de que o pesquisador se municia para abordar a realidade pretendida.

Parte fundamental do trabalho sociológico orienta-se no sentido de romper com as categorias de percepção do senso comum (BOURDIEU, 2012). Sem uma discussão teórica acerca dos conceitos com os quais estamos trabalhando tomaremos a realidade e seus componentes através das mesmas categorias utilizadas pelo senso comum (aquelas que dão condições para a reprodução do mundo tal como se faz crer). Ao observar um indivíduo sem esta problematização, a atenção se deterá em seu trajeto, na sequência de suas ações, expressões, encontros, enfim, tudo o que entendemos como sendo propriedades decorrentes de um indivíduo de acordo com o paradigma sob o qual trabalhamos (saibamos ou não). Mas não necessariamente nos questionaremos sobre o que é um "indivíduo". Ao fazê-lo nos depararemos com uma série de problemas. Para Lahire, por 
exemplo, "o indivíduo, o foro íntimo ou a subjetividade como local de nossa liberdade primordial, é um de nossos grandes mitos contemporâneos" (LAHIRE, 2004, p. XIII). Também Hall demonstra que esse "sujeito cartesiano, autocentrado, unificado, dotado das capacidades de razão, cujo 'centro' consistia num núcleo interior” (2011, p. 11), é sobretudo uma construção do Iluminismo. Tendo em conta tais críticas, como prosseguir observando "o indivíduo"? Para qual definição conceitual nosso trabalho sinaliza? Qual o nivel em que um agente atinge alguma existência, visto que no nivel conceitual ele tem problemas quanto a sua validade?

Esse mesmo estilo de discussão pode ser visto na investigação dos conflitos intergrupais que Norbert Elias elaborou em Os estabelecidos e os outsiders (ELIAS, 2000). Elias fora requisitado a pesquisar os motivos de alguns grupos cometerem "atividades delinquentes" na comunidade de Winston Parva. Já na época em que chegou à comunidade constatou que quase não havia mais tais ocorrências, mas que o grupo identificado como "delinquente" continuava recebendo aquele rótulo por parte do outro grupo. Segundo o autor, a pesquisa se viu obrigada a construir novos conceitos relativos a "grupos sociais", pois, ao contrário da existência de uma cisão que explicasse o antagonismo entre os mesmos, o autor encontrou uma relação na qual "os indivíduos que fazem parte de ambos os grupos estão, ao mesmo tempo, separados e unidos por um laço tenso e desigual de interpendência." (ELIAS, 2000, p. 8)

Direcionando a discussão sobre os "estabelecidos" e "outsiders" de Elias para os conflitos entre "gaúchos" e "baianos" em Rio Grande, levantouse os seguintes questionamentos: há uma intersecção entre eles? Como se constituem as nuances que integram os relativos intervalos de seu antagonismo? Como se afetam? Como me situo nessa disputa enquanto pesquisador e enquanto sujeito socializado?

Os conflitos em Rio Grande assumiram graus e formas diversas. Por vezes bastava chegar à cidade, pegar um ônibus ou taxi, aguçar o ouvido para as conversas do ambiente para tomar conhecimento de sua existência. A proporção das brigas acabaram por alcançar a esfera pública, inundando 
a internet e os meios de comunicação com seu conteúdo (o que, por sorte, acabou por enriquecer minha pesquisa sem cobrar grandes esforços se não o de converter todo este conteúdo em dados analisáveis ${ }^{2}$ ).

No centro deste embate estava a construção e abertura de postos de trabalho no polo naval de Rio Grande, empreendimento que atingiu a dinâmica da região pelo seu peso e pelas redes que acionava a nível global, posto que se destinava à construção de plataformas para a exploração de petróleo e gás na costa do país. Os sindicatos, as instituições de qualificação e treinamento dos trabalhadores, o comércio e toda a rede que se articulava a estes megaempreendimentos, também foram afetados. Portanto a primeira preocupação era compreender porque estavam ocorrendo conflitos no âmbito da instalação do polo naval entre trabalhadores locais - que se sentiam prejudicados - e estrangeiros - que apresentavam queixas de xenofobia.

As primeiras postulações iam em direção às supostas disputas materiais e simbólicas em relação aos recursos já disponiveis localmente junto àqueles advindos com o polo naval. Pois, apesar da força com que o rótulo "baiano" aparecia nos discursos locais, o sujeito mesmo que o termo buscava representar simplesmente não existia, remetendo a um conjunto de práticas aleatórias e dispersas demais para consolidar uma identidade contrária. Os "baianos" diziam respeito antes a impulsos de manutenção de uma realidade desestabilizada pelos efeitos trazidos com o polo, e que atingiam tanto a realidade objetiva quanto o espaço subjetivo dos habitantes locais.

Trabalhando com postulados ao invés de hipóteses, também obedeci a um programa cíclico de pesquisa, no qual as perguntas geralmente esboçadas em momentos de análise dos dados são novamente levadas a campo para testar sua força e transmutá-la em asserções. Por exemplo: “a identificação do ‘baiano’ é feita através do traço de cor/raça/etnia?”, caso a resposta fosse afirmativa a pergunta se transformaria em uma afirmação. Desse modo a prática de pesquisa ganha um movimento ascendente, em que as idas e vindas a campo se depuram a cada nova imersão, se corrigem, se

\footnotetext{
${ }^{2}$ Destaco o uso do programa N-Vivo pelo qual pude organizar e padronizar todo tipo de material que encontrei na internet.
} 
Relatos sobre uma etnografia no Polo Naval de Rio Grande | Pedro Marchioro

afinam, em uma espiral que evolui em direção ao aumento da correspondência entre os conceitos advindos do campo e as próprias manifestações sucessivas do mesmo.

O quadro teórico advindo dos conceitos e categorias formados no próprio campo se denomina "teoria fundamentada" (QUIÑONES, 2015). Neste tipo de teoria, os conceitos mantem diálogo constante com a realidade em que foram formulados, abrindo-se aos ajustamentos que se mostrem necessários. No tópico seguinte trarei um relato de como utilizei da etnografia na pesquisa realizada entre 2014 e 2016 para a minha dissertação de mestrado.

\section{Uma etnografia do etnógrafo}

Se avançarmos teoricamente na superação da (falsa) dicotomia entre corpo e espírito, ou afetos e razão (HALL, 2011), tornar-se-á imponderável pensar o pesquisador enquanto aquele que reserva a produção do conhecimento apenas à sua consciência racional como antítese das afecções do corpo. Uma vez que não se pode retirar a subjetividade do jogo da pesquisa, há que se convertê-la em ferramenta estratégica para a mesma. Mas como distingui-la das simples generalizações de impressões apreendidas em experiências pessoais, tal como o faz o senso comum? Uma das maneiras é submetê-la aos mesmos procedimentos com que abordamos nosso universo de análise, ou seja, fazer uma sociologia de si mesmo, uma sociologia do sociólogo (BOURDIEU, 2011). Seguirei o texto buscando fazer esse exercício.

Nosso corte digressivo vai até finais de 2014, ano que marcou o fim de minha graduação em ciências sociais e início do processo de seleção do mestrado para o qual desejava me candidatar. Já muito próximo à data de inscrição, eu ainda não havia delineado um problema de pesquisa. Correndo contra o tempo, podia contar com uma pouca experiência que se concentrava nas questões trabalhistas, muito forte na universidade em que se deu minha formação, e era para esse universo que se direcionava minhas esperanças de produzir um projeto de pesquisa para disputar uma entrada 
no programa. O mal dessa inexperiência, como mais tarde viria a verificar, é que a insegurança, a imaturidade e a ansiedade que acompanham o pesquisador recém-formado, não nos deixa entrever as inúmeras possibilidades de trabalhar um problema - qualquer problema - em matéria de pesquisa sociológica.

$\mathrm{Na}$ graduação havia pesquisado os conflitos em torno da terceirização do trabalho, basicamente transcrevendo e analisando os discursos dos agentes em disputa. A conselho de meu orientador com quem trabalhava naquele período, passei a ler autores como Bourdieu, Schutz, Goffman para equipar as análises dos discursos. Estas leituras acabaram por extrapolar o âmbito da pesquisa, lançando-me a pensar situações cotidianas, "banais", que, de repente, manifestavam-se com mais riqueza e complexidade do que de costume. Já existia aí, de certo modo, ambições no sentido de fazer um trabalho etnográfico, mesmo que a estreiteza de meu horizonte, na época, frustrasse de antemão a possibilidade de convertê-la em prática de pesquisa. Retomando os diários de campo desse período, revejo inúmeras anotações em que exercitava a centralização de situações e objetos comuns: o modo como as pessoas atribuem significados bastante distintos aos mesmos objetos, a maneira de andar, a possibilidade de deduzir a proveniência social através de traços comuns, etc. Entretanto, apesar destes interesses genuinos, havia a necessidade de formular um projeto que trouxesse um objeto "importante" para o ingresso no mestrado. O polo naval já aparecia como universo de análise (era quase impossivel não fazê-lo dada sua reverberação naquele contexto) porém ligado à composição das empresas, ao trabalho imigrante, etc.

\section{A (re) construção estratégica do campo}

A inversão dessa situação ocorreu em um momento raro, de total relaxamento e abandono daquelas preocupações. O gancho me foi dado por um informante aleatório: uma cabeleireira, em Pelotas, a qual há algum tempo vinha me concedendo seus serviços. Em uma das tardes em que recorri ao seu salão, ao "fofocar" sobre seu novo namorado policial, confidenciou-me que achava "muito justo" que a polícia "caga-se a pau 
aqueles 'baianos', nojentos e lambuzados que tinham vindo trabalhar no polo".

Há uma noção comum de que os salões de beleza, outrora direcionados exclusivamente ao público feminino (e talvez por isso), seriam antros de fofocas. Afora a pecha sexista que atua aí, um etnógrafo pode verificar com facilidade que os lugares em que há mais densidade de "fofoca", guardam peso significativo para a compreensão das relações e das representações sociais locais. Norbert Elias descobriu com grande entusiasmo essa propriedade em seu estudo de caso sobre a comunidade de Winston Parva (2000). Assim, foi em uma atividade trivial e na atmosfera despreocupada do salão de beleza que foi disparado o tão caro e ainda coxo problema que iria projetar minha pesquisa ${ }^{3}$.

Da junção da fala da cabelereira com a minha recepção produziu-se um acontecimento: a realidade em que me encontrava passou a configurar um "campo estratégico de pesquisa" (WACQUANT, 2002, p. 24), ou seja, um lugar prenhe de informações em que eu deveria me inserir e explorar. Por "minha recepção" quero destacar o peso da formação no trabalho do pesquisador. $\mathrm{O}$ etnógrafo pressupõe alguém com uma formação específica, no sentido de deter um senso prático, um conjunto de ferramentas que o capacitam a transformar seus encontros em questionamentos, classificações, perturbações que the atingem o corpo e que podem ser transfiguradas em problemas de pesquisa (BORUDIEU, 2011). Nesse sentido ele não está acima ou observa mais reflexivamente os fatos do que os demais atores envolvidos. Tanto ele quanto os outros estão clivados de dimensões subjetivas (LAHIRE, 2004), de forma que também o etnógrafo é um agente social tal como os outros, com vícios e paixões, que sente aversão, ciúmes, ódio, que tem preferências e antipatias. A diferença é que ele traz essas impressões para o âmbito científico justamente pela particularidade de sua formação, essa quase "segunda natureza", isto é,

\footnotetext{
${ }^{3}$ Vale adicionar que o período era de angustia por estar encerrando o prazo de envio do projeto para entrada na seleção de mestrado, de modo que sou muito grato a esta pessoa que não somente me auxiliou nesse momento, mas ao longo de toda a minha pesquisa, assumindo o papel de desencadear entrevistas em bola de neve, assim como de liberação de um grupo focal, informal e espontaneamente acionado em uma tarde de sábado e que liberou problemáticas que deram corpo a um capítulo inteiro de minha dissertação.
} 
uma natureza socialmente constituída através de um árduo e contínuo trabalho de aperfeiçoamento (BOURDIEU, 2011). Também por esse motivo é que não vemos os preconceitos, as irritações, as emoções, as hesitações menos nobres de antropólogos e sociólogos em seus textos oficiais, por haver esse trabalho de tradução, depuração e limpeza.

Nesse caso, a imersão prolongada em campo foi muito importante para gerar a sensação de estar preparado para adentrar a lógica do universo em que estava interessado, ou seja, a configuração em que os "baianos" e os "gaúchos", cada um a seu modo, ganhavam sentido. Nutrido de considerável leitura de outras experiências etnográficas, passei a exercitar o estranhamento dos fatos que considerava "banais", atribuindo a todos algum valor de registro e análise, mesmo que não apresentassem relevância alguma para os nativos ("Rio Grande sempre teve disso" costumavam dizer quando os interpelava sobre alguns fatos). Sendo assim, sentia a necessidade de avançar na compreensão daquele campo cujos códigos pareciam-me desordenados, só a partir de então poderia levantar alguns problemas. A construção dos problemas de pesquisa a partir do próprio campo é um modo seguro de não incorrer naquela "imposição da problemática" de que falava Bourdieu (2011), a saber, de questionar os atores sociais sobre problemas que não existem senão para o pesquisador.

O cumprimento prolongado da estadia em campo, foi-me facilitado pelo empréstimo de uma casa, concedida por um colega ${ }^{4}$ de mestrado, na praia do Cassino, a alguns quilômetros do centro de Rio Grande. Muitos estrangeiros se concentravam por ali, já que o polo naval ficava próximo e o valor dos imóveis eram mais vantajosos. A proximidade proporcionou grande margem para testar todo tipo de hipóteses já que a prontidão do campo não me deixaria levantar voos altos demais, ao mesmo tempo em que me dava alguma segurança para fazê-los.

Passei a mapear os lugares que os nativos e os estrangeiros frequentavam. Iniciei a fase da observação, do caminhar e sentir a cidade, os lugares possíveis de ver um e outro para, posteriormente, entrevistá-los. Pouco a pouco a topografia das relações foi se delineando: os nativos

\footnotetext{
${ }^{4} \mathrm{O}$ grande amigo, a quem não me canso de agradecer, é Fernando Freitas.
} 
tendiam a se concentrar em espaços tradicionais, enquanto os estrangeiros difusos percorriam as margens, moravam longe dos centros, iam a bares e cafés menos conhecidos.

Do mesmo modo, fui verificando que o rótulo "baiano" era parte de um processo mais geral que remetia aos esforços de reorganização da realidade local desestabilizada pelo polo naval, a que os nativos procuravam restaurar através de signos explicativos. Ajustei então o foco da pesquisa para a população local e o modo como essa nova realidade era percebida por eles: deveria agora reconstruir o "baiano" através dos sinais emitidos pelos nativos. É dizer que de alguma forma deveria incorporar sua perspectiva, pois a perturbação provocada pelo estrangeiro, enquanto elemento transgressor, estranho, não é efetuada em niveis racionais e conscientes para o nativo. Assim, de alguma forma também deveria me apropriar destes princípios sensoriais de distinção do "baiano" quando presente.

Assim como a lógica do espaço em que vive não é conscientemente obedecida pelo nativo, também aquilo que a viola não o pode ser. Aquilo que denominamos senso prático, ou a natureza social, requer um trabalho prolongado de aprendizado e treinamento (que tende a ser apagado, naturalizado). Se aproximarmos a escala de análise para o nível individual, perceberemos que todo o agente domina um volume considerável de regras complexas sem se dar conta que o faz, portanto, de forma pré-reflexiva, simplesmente "sentindo-as" (isso aparece nas observações e entrevistas geralmente quando os agentes não conseguem explicar aquilo que sentem). Dessa forma, pois, quando questionado repentinamente sobre os motivos de não gostar do "baiano", na maioria das vezes não havia uma explicação clara. As respostas vinham em termos emocionais, na elevação do tom de voz, na inquietação, na revolta entre a obviedade da resposta e a incapacidade de verbalizá-la para esse sujeito "importuno" (o pesquisador) que o questiona 5 .

\footnotetext{
${ }^{5}$ É nesse estágio, quando o elemento estranho atingiu um significado mais ou menos inteligível e comunicável para os agentes da comunidade, que se pode dizer que ele passou a fazer dos signos que compõem sua realidade. Nesse momento, quanto mais distribuído e naturalizada estiver a sua existência, mais ele tenderá a ser autoexplicativo, ou seja, inapto à ser claramente descrito por aqueles que o utilizam.
} 
A vivencia prolongada, aquilo que se denomina "participação observante" (CARDOSO, 2004), pode ser entendida pelo trabalho de sujeição do corpo, por parte do etnógrafo, ao campo. É como se o etnógrafo emprestasse o corpo para que aquele espaço, com suas lógicas, se inscrevesse nele, para depois extrair daí suas impressões. Dado que toda afecção, toda emoção sentida subjetivamente encontra seu princípio no espaço social objetivo, e que a vivência prolongada exige do corpo alguma forma de incorporação (BOURDIEU, 2012), pode-se afirmar que toda emoção, impressão, sentida pelo etnógrafo pode ser tomada como uma possivel informação para a compreensão do universo de onde ela é oriunda. Assim, a certa altura da pesquisa, ao acompanhar parte do trajeto de um "baiano", eu podia observar e medir o grau de cumprimento de um indivíduo com aquele estereótipo a partir não só dos sinais que os nativos emitiam em sua passagem, mas de minhas próprias impressões. Pude compreender melhor o que é que os incomodava, que não se encaixava no quadro ordenado daquilo que entendiam como "normal", "certo", "desejável", "bom". Devemos cuidar, no entanto, em não nos abandonarmos por completo ao universo investigado, para não incorrermos nos mesmos atos dos nativos. Vale salientar que a história da etnografia é prenhe de casos dos pesquisadores que "foram e não voltaram mais"' (WACQUANT, 2002).

Uma vez que para agir com "naturalidade" em campo o etnógrafo precisa incorporar a lógica do campo a um nivel sensivel, pré-reflexivo, e portanto se oferecer à transgressão de sua própria natureza social, a etnografia envolve também uma ética. Segundo Lahire (2004) isso acarreta algum grau de sofrimento, de neurose, dado que demanda um exercício de constante refreamento e reflexão interna por parte do sociólogo. É, pois, somente no momento em que o pesquisador se sente parte daquele universo que ele está à vontade e preparado para prosseguir nos próximos passos da pesquisa, afinar as observações e formular as entrevistas. No meu caso, em minhas primeiras tentativas houve grande dificuldade em realizá-las. Não foram poucas as vezes em que passei horas observando um grupo sem

\footnotetext{
${ }^{6}$ Em seu livro sobre o boxe, Wacquant nos diz em rodapé que quase desistiu da carreira de sociólogo para tentar a vida de boxeador profissional.
} 
conseguir adentrá-lo. Em outras vezes consegui uma hora de entrevista gravada, porém sem nenhuma informação relevante. $O$ sentimento de segurança foi aumentando conforme incorporava mais intensamente o cenário local.

A entrevista exige mais do que a disposição de escutar por parte do entrevistador. Aprendi que o modo como o entrevistado responde a determinada questão que o pesquisador lhe coloca, depende também das situações em que ele se encontra (se está no trabalho, na rua, no shopping, se é domingo, se está com fome, cansado, etc.). Há manuais que aconselham a controlar estes fatores externos: que escolhamos o dia adequado, o lugar, etc. (GUBER, 2011; QUIÑONES, 2015). Todavia, ao primeiro contato com o campo podemos nos deparar com o fato de que só nos resta contar com a improvisação.

\section{A "cozinha" da pesquisa}

A transcrição pura e simples do material colhido nas entrevistas não diz muito por si só. Há que se valer de técnicas de demonstração de como os dados são produzidos e analisados. A etnografia, enquanto conjunto de técnicas qualitativas, não termina na análise dos registros, mas na formulação do texto escrito. Os trabalhos que se desenvolvem sobre esse viés exercem um estilo, uma linguagem e uma escrita diferenciada. Aos primeiros contatos com os textos de viés etnográfico, a impressão que tive foi que eram como um lago de águas claras em comparação com os textos duros e intrincados da sociologia tradicional. O estilo é mais livre e solto, e permite uma aproximação com o universo reflexivo da totalidade dos envolvidos: autor, interlocutor e leitor (GUBER, 2011). Isso não necessariamente indica alguma facilidade para o pesquisador/escritor. Entra em jogo aqui, além da dimensão ética, a variável estética em que o trabalho etnográfico é veiculado, de uma preocupação adicional com o leitor. A esse respeito, vale a transcrição literal do estilo de Wacquant em seu estudo sobre o boxe:

[A etnografia] deve se esforçar para capturar e restituir essa dimensão carnal da existência, (...) através de um trabalho metódico e minucioso de detecção e de registro, de decodificação e de escritura 
capaz de capturar e transmitir o sabor e a dor da ação, o som e a fúria do mundo social que as abordagens estabelecidas das ciências do homem colocam tipicamente em surdina, quando não os suprimem completamente. (...) os modos de escrita, mas também o uso estratégico das fotos e anotações pessoais, responde a esse cuidado de fazer o leitor entrar no cotidiano sensual e moral do pugilista comum, de fazê-lo palpitar ao longo das páginas junto com o autor, de modo a lhe fornecer todo o conjunto e a compreensão arrazoada dos mecanismos sociais e das forças existenciais que o determinam e a aisthesis particular que ilumina sua intimidade de combatente (WACQUANT, 2002, p. 16)(itálicos meu).

Para Florence Weber (2009) "o saber-fazer do etnógrafo é também um saber-escrever" (WEBER, 2009, p. 161). A autora sugere três ou quatro tipos de diários que podemos manter durante a pesquisa: um para os dados mais formais da pesquisa, um diário formal, e um "diário íntimo" em que seriam depositados os humores e emoções menos "publicáveis" (WEBER, 2009). Em minha experiência atravessei esses niveis de preocupação em um mesmo caderno, desde a liberação da imaginação até a atenção estreita unicamente ao observado. Pois, como dito anteriormente, o lugar da pesquisa é sempre imprevisível, e pode haver situações em que não se dispõem de mais instrumentos para anotação do que uma nota fiscal do supermercado ou um guardanapo emprestado de um café.

Tampouco há disponibilidade de tempo para passar a limpo toda a sorte de anotações nos cadernos específicos para cada código. A limpeza e filtro da bagunça são feitas em situações adversas, de retorno para casa ou na própria redação final dos textos. Em meus diários pode-se mesmo encontrar desenhos e rabiscos feitos em horas de tédio enquanto esperava o desenrolar vagaroso de determinada situação (e que não são de todo inúteis!). Como já colocado, o próprio disparador de meu problema de pesquisa foi-me lançado em uma situação completamente improvável, em que eu não dispunha de nada a mão e tive que carregá-la correndo na memória até o café mais próximo.

Também não vejo razões necessárias para considerar alguns estilos de escrita ou tipos de registros publicáveis e outros não (com a exceção do critério referente ao público visado). Como pesquisador gostaria de encontrar mais relatos de pesquisadores quanto aos níveis pessoais envolvidos na pesquisa e que podem lançar luz sobre as vicissitudes insuspeitas impostas 
pelo campo. Howard Becker defende um rompimento com tais imperativos sem mais razão de ser do que a simples arbitrariedade tornada real pela obediência com que a observamos:

\begin{abstract}
Os cientistas sociais começaram a contar histórias pessoais quando reconheceram que a apresentação impessoal de ideias e resultados de pesquisa, a qual costumava ser considerada científica, oculta aos leitores fatos que eles gostariam de conhecer. A maioria dos textos sociológicos se concentra na maneira como foi feita a pesquisa, e a redação merece o mesmo tipo de atenção (BECKER, 2015, p. 128).
\end{abstract}

\title{
Considerações finais
}

Ao acionar as mesmas categorias do senso comum para descrever a realidade social em que se dão as relações de trabalho, as instituições acabam por reproduzir suas desigualdades e assimetrias. Nesse sentido cabe ao trabalho etnográfico medir a validade das mesmas e reconstruir categorias e conceitos que se mostrem mais alinhados ao universo de análise. Esse modo de construção conceitual a partir do trabalho de campo enquadra a teoria fundamentada, isto é, um quadro interpretativo desenvolvido a partir da realidade em que os dados foram levantados e aberto a constantes diálogos e ajustamentos com a mesma.

A etnografia não se encerra na coleta e análise de dados. Uma vez que se põe à crítica a (falsa) dicotomia entre a razão consciente e o corpo afetivo, a subjetividade do pesquisador passa a contribuir como recurso de elevada força heurística no processo da pesquisa. A apreensão do universo investigado exige a incorporação de sua lógica por parte do etnógrafo. Há, portanto, uma dimensão ética de superação de sua própria natureza e de apreensão do universo alheio, isto é, de oferecer seu corpo como lugar de registro das demarcações de dado espaço social para a produção de conhecimento.

Cabe ainda ao etnógrafo a responsabilidade de levar a pesquisa para que o leitor a reviva integral e sensualmente em seu processo. Nesse sentido, junto a aventura que a etnografia proporciona ao imaginário do pesquisador, soma-se a variável estética, de exercício da escrita e da sensibilidade vinculada à mesma. Assim, pode-se afirmar que a pesquisa etnográfica 
atravessa pelo menos três universos reflexivos: o do pesquisador, o da pesquisa e o do leitor. Desse modo, como sujeito sensivel, "abandonado" ao universo da pesquisa, o etnógrafo deve prezar pela capacidade de trazer o leitor para a realidade em que a pesquisa se desenvolveu, de evidenciar não somente seus resultados finais, depurados de toda a "sujeira" que o trabalho em campo necessariamente encerra, mas seu processo de fabricação, o movimento interno de sua "cozinha".

\section{Referências}

BECKER, Howard. Truques da escrita: para começar e terminar teses. - Rio de Janeiro: Zahar, 2015.

BOURDIEU, Pierre. Coisas Ditas. - São Paulo: Brasiliense, 2004.

2011.

O poder simbólico. - Rio de Janeiro: Bertrand Brasil,

CARDOSO, Ruth. Aventuras de antropólogos em campo ou como escapar das armadilhas do método. In A aventura antropológica. - São Paulo: Paz e Terra, 2004.

ELIAS, Norbert. Os Estabelecidos e os Outsiders: sociologia das relações de poder a partir de uma pequena comunidade. - Rio de Janeiro: Zahar, 2000.

GUBER, Rosana. La etnografia: Método, campo y reflexividad. - Buenos Aires: Siglo Veintiuno Editores, 2011.

HALL, Stuart. A identidade cultural na pós-modernidade. - Rio de Janeiro: DP\&A, 2011.

LAHIRE, Bernard. Retratos Sociológicos: disposições e variações individuais. Porto Alegre: Artmed, 2004.

QUIÑONES, Mariela. Los procedimentos de análisis de la teoria fundamentada. In:_. Introducion a la sociologia cualitativa. Universidad de la Republica, 2015.

WACQUANT, Loïc. Corpo e alma: notas etnográficas de um aprendiz de boxe. - Rio de Janeiro: Relume Dumará, 2002.

WEBER, Florence. A entrevista, a pesquisa e o íntimo, ou: por que censurar seu diário de campo? In: Horizontes antropológicos, porto alegre, ano 15, n. 32, p. 157-170, jul./dez. 2009. 